\title{
Human activities, climate changes affect marine populations
} \author{
Louis W. Botsford
}

The combination of offshore flow and the nearshore jet, in conjunction with California's irregular coastline, influences temperature and phytoplankton growth. Pictured is

Crescent City.

\begin{abstract}
Upwelling of nutrient-rich waters makes California's coastal ocean one of the most productive in the world. Better understanding of the year-to-year changes in populations due to EI Niños, and recent awareness of decade-to-decade widespread changes in the ocean and atmosphere, have improved our ability to project the effects of fishing and climate change on marine populations. On smaller scales, we are also finding that weekly changes in upwelling winds cause coastal currents to deliver planktonic larvae to the coast in spatial patterns. Additional research is vitally needed to reduce the uncertainty in population prediction that allows political pressure to lead to overfishing and confounds recovery planning for endangered species such as salmon.
\end{abstract}

Gew Californians are aware that our 1 coastal ocean is one of the most biologically productive in the world. It is one of the world's four major upwelling areas, located on the eastern boundaries of the Pacific and Atlantic basins, in both hemispheres. The broad (600-mile-wide) southward flow of waters off our coast, the California Current, is thus similar to the Humboldt Current along Chile and Peru, the Benguela Current off southern Africa and the Canary Current off northern Africa, all of which are characterized by strong upwelling and high fisheries productivity. Although these eastern boundary currents comprise only a small percentage of the total area of the global oceans, they are responsible for $40 \%$ of the world's fish harvest.

Even though we understand the fundamental reason that these areas are so productive, we need a much better understanding of why the biological populations within each eco- system fluctuate so dramatically from year to year and over decades. Until we understand the forces that drive these natural fluctuations, it will continue to be difficult to separate them from the changes that are being caused by human activities, such as pollution, overfishing, deterioration of the freshwater habitat of salmonids and climate change through the greenhouse effect.

Over the past several decades we have made significant advances in our understanding of how varying physical conditions drive changes in biological populations along the coast. With increasing interest in marine research due to concern for declining populations and possible changes in climate, even greater advances may soon be possible, enabling us to manage these resources better.

\section{The physical setting}

Along the California coast, upwelling occurs when strong winds 
blow from the north. Because of the earth's rotation and the resulting Coriolis effect, these winds cause surface waters to flow away from shore and are the indirect cause of a rapid, nearshore current called a coastal jet. Next to the coast, this movement of surface water offshore leads to its replacement by water from the bottom, which is both cooler and richer in nutrients. The combination of offshore flow and the nearshore jet, in conjunction with the irregular shape of the coastline, leads to the exotic patterns of temperature and phytoplankton growth that oceanographers first began to see in satellite images in the 1970s (fig. 1).

The primary biological effects of upwelling are: (1) greater biological

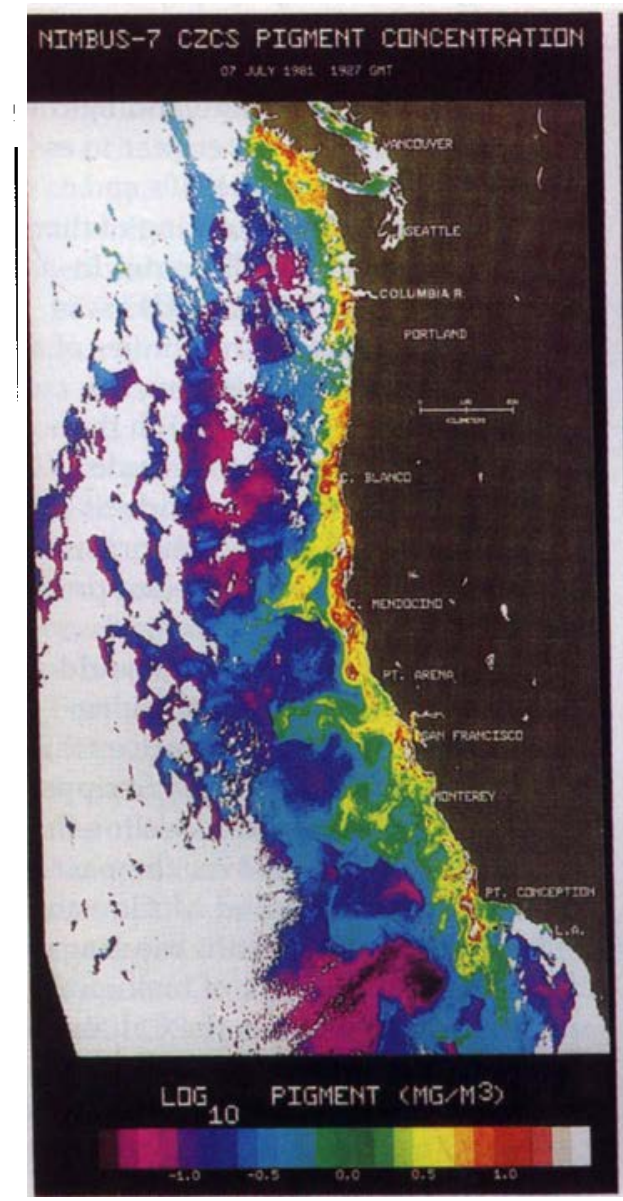

27.1. Nimbus-7. Orbit 1348. 7 July 1981 CzCS Falue-Cotor Pigment Image. productivity; (2) transport of biological organisms; and (3) a decrease in water temperature, which generally slows biological processes. Of these, the increase in productivity by microscopic plants called phytoplankton is usually considered most important by oceanographers. Movement of organisms may be just as important, however, although the effects of transport may not be positive. To be successful, the planktonic larvae of fish and benthic invertebrates must avoid being swept to the south or offshore during the upwelling season (Parrish et al. 1981).

Upwelling varies weekly, seasonally and annually, and along the coast. In California, the upwelling season is the spring and early summer, during

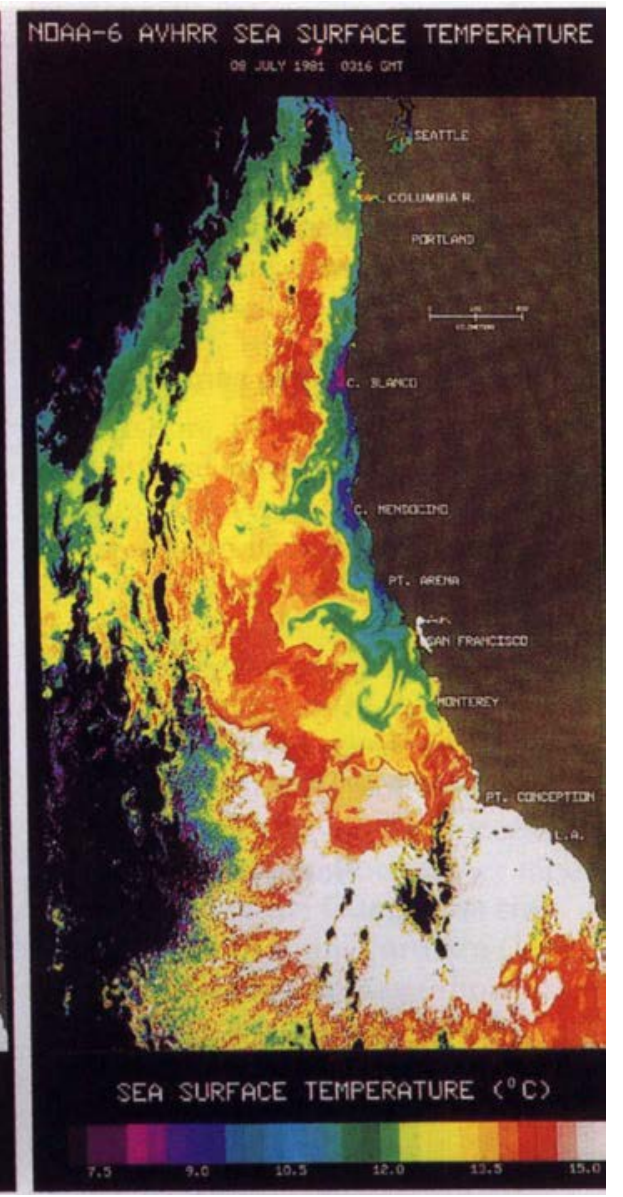

27-2. MOAA-6. AVHRR. \& Juby I94 False-Color Sea Surface Temperature Image.

Fig. 1. (a) Data from the satellite instrument called the Coastal Zone Color Scanner, indicating the pattern of primary productivity (phytoplankton abundance) on July 7, 1981. (b) Data from the Advanced Very High Resolution Radiometer, Indicating ocean temperature on July 8, 1981. During the upwelling season, primary productivity is generally higher and temperatures are cooler near shore, but this pattern is interrupted by strong offshore flow near points such as Point Arena. (Figure by M. Abbot and P.T. Strub of Oregon State University.)

which time the phenomenon typically occurs in bouts of a week to 10 days, with slightly briefer periods of relaxation from upwelling between episodes. Along the coast, upwelling is weak in Southern California and strongest just north of San Francisco, but still strong near the California/Oregon border.

The amount of upwelling varies from year to year with the strength and duration of winds during the spring. Until 15 to 20 years ago, variation in upwelling was considered the primary physical mechanism determining the productivity of California's fisheries from year to year (Reid 1962).

We have come to realize that another major influence on the physics and biology of California's coastal ocean is the occasional occurrence of events called El Niños. On California's coast, El Niños are manifested as 1- or 2-year periods with warmer temperatures, higher sea levels, a weaker California Current and lower biological productivity than usual. El Niños occur in both hemispheres; in fact they received their name (Spanish for "the Child") in South America because they typically occur near Christmas. El Niños are initiated by a weakening of the tradewinds near the equator, which allows the water "piled up" (that is, slightly higher sea level) on the western side of the Pacific to "slosh" back to the eastern side, increasing sea level and seawater temperatures at the coast. The higher sea level spreads northward and southward along the coast, and temperatures increase. Another name for this phenomenon is ENSO, El NiñoSouthern Oscillation; the term southern oscillation refers to the atmospheric pressure change that leads to the relaxation in the trade winds.

Appreciation of the effects of ENSO events has increased over the past 20 years. The dramatic effects of the 1982-1983 ENSO were the first to draw attention in time for research efforts to be mobilized to study the phenomenon (Wooster and Fluharty 1985). As sea levels and ocean temperatures began to increase to unusually high levels in 1982, marine 
scientists in Southern California began to study the large 1982-1983 El Niño, in part with Sea Grant funding. Scientists found that this El Niño was accompanied by changes in the depths of water layers, a decline in nutrients, lower zooplankton biomass and (in contrast to the 1957-1958 El Niño) low salinities, with dramatic declines in kelp forests and their associated species (Tegner and Dayton 1991).

In the early 1980 s, scientists from Scripps Institution of Oceanography proposed that the relationship between the total weight (or biomass) of zooplankton and cooler temperatures was due not to upwelling, as had previously been thought, but to stronger southward flow of the California Current during non-ENSO years. The variability in the southward transport of subarctic water appeared to be related to changes in the relative amount of the North Pacific Current (the current that flows eastward across the Pacific from Japan), which splits to flow northward in the Alaska Current and southward in the California Current.
Another important recent finding is that ocean conditions also change on broad spatial scales, over longer time scales than the 5-to 10 -year variability in ENSO. In some locations, atmospheric and ocean conditions, plus the associated marine ecosystems, appear to change in a fundamental way every 30 to 60 years. Such changes from one oceanographic regime to another are called regime shifts. A recent example is the dramatic shift in a number of atmospheric and oceanographic variables in the North Pacific coincident with intensification of the Aleutian low-pressure system in the mid-1970s.

\section{The biological response}

We are now beginning to understand how changes in physical conditions affect the fish and shellfish populations residing in California's coastal ocean. Oceanographic conditions have the most profound effect on the numbers of individuals of a species that make it through the free-floating planktonic larval phase each year to join the juvenile and adult population

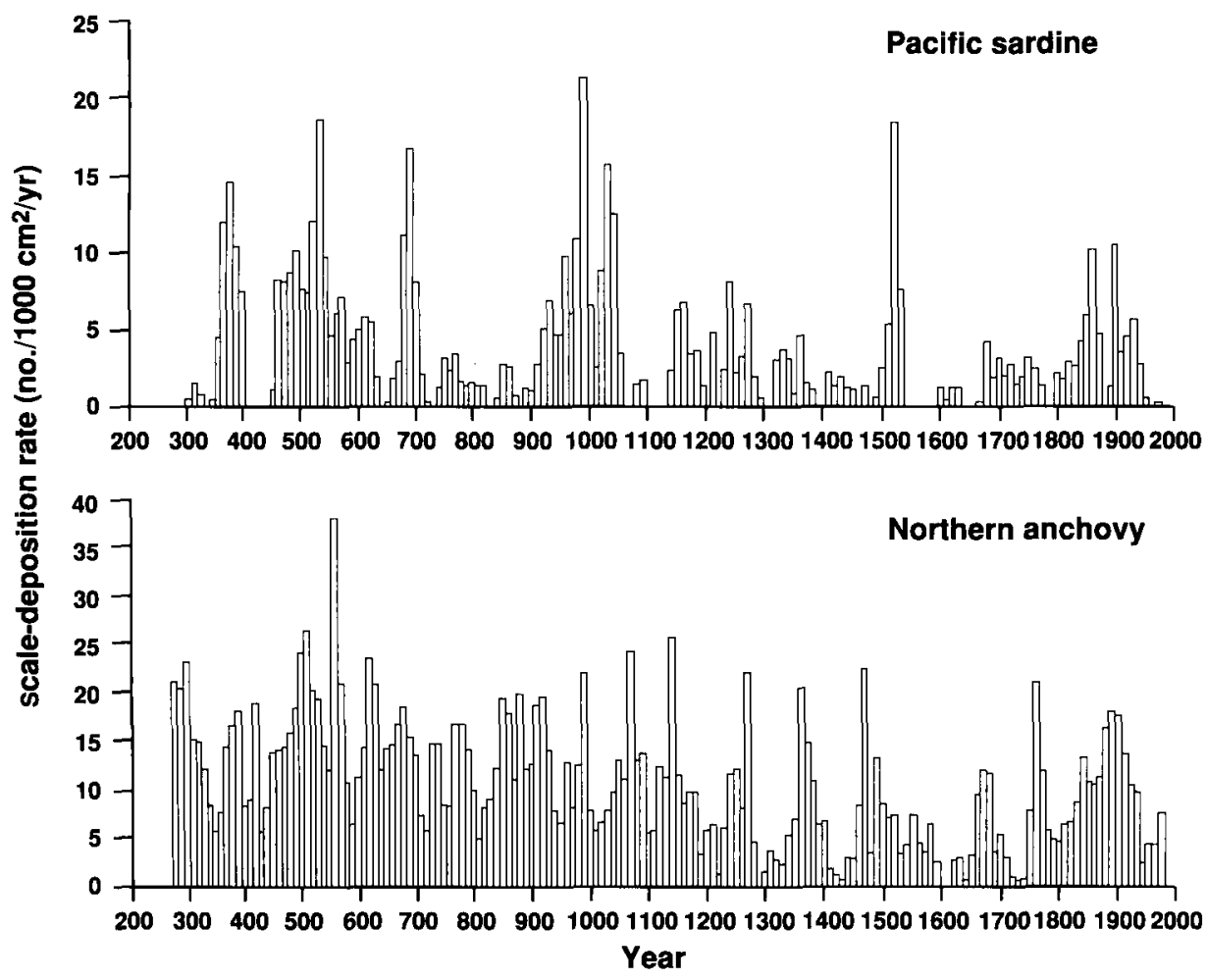

Fig. 2. Deposition rates of fish scales from the Pacific sardine and the northern anchovy from anaerobic sediments in the Santa Barbara Basin over the past 1,700 years. These rates of fish scale deposition were proportional to population abundance of these specles. (From Baumgartner et al. 1994.) (a process referred to as recruitment). For most marine fish there is a critical period near the time at which the larval yolk sac is completely absorbed and the fish must begin to fend for themselves. At this time the fish must have adequate available food, and they must be at, or on their way to, a favorable location (in terms of predators, habitat and so on). Poor recruitment is usually the result of one of these conditions not being satisfied. A well-known example in the California Current is the fact that anchovy larvae require periods of relatively calm weather so that high enough food densities for them to feed adequately can develop, an effect named for its discoverer, Reuben Lasker, a prominent NMFS scientist (Mullin 1995).

Biological oceanography in the California Current really got started during the decline of the sardine fishery (which collapsed from landings of 700 million metric tons per year to essentially zero in the late 1940s and early 1950s) with the founding of the California Cooperative Fisheries Investigation (CalCOFI). CalCOFI was founded to coordinate the studies of a number of institutions seeking the causes of this decline, although the program has expanded to include many other species and to address many other topics in the California Current. The CalCOFI sampling program, carried on over the past 50 years, is one of the best in the world. One example of the value of a longterm monitoring program such as this is the recent identification by Scripps scientists of the dramatic decline in zooplankton biomass over the past 30 years (Roemmich and McGowan 1995). The annual scientific meeting of CalCOFI is a focal point of biological and physical research in the California Current, and much of the Sea Grantfunded research on fisheries oceanography and marine policy is reported and discussed there.

The cause of the decline of the sardine is still not known with certainty. It is unlikely that it was due to overharvesting, although the population probably would have recovered more rapidly if it had not been so heavily harvested. A fascinating source of in- 
formation on this fishery is the deposits of fish scales in the sediments in the Santa Barbara Basin. The relative abundance of scales of sardines, anchovies and hake at each depth are a record of population fluctuations in each of these species over the past 2,000 years (Soutar and Isaacs 1974) (fig. 2). Sea Grant-funded scientists are trying to determine whether these changes could be related to past climate change (Baumgartner et al. 1994).

Marine scientists have recently begun to realize that similar fluctuations in fish populations occur at the same time even though the populations are on different sides of the ocean or in different hemispheres. For example, the Kuroshio-Oyashio sardine off Japan was at high levels over the same time as the Pacific sardine off California, and it has recently increased again to high levels at the same time as the sardine in the California Current. These changes are thought to be due to changes in physical conditions (regime shifts), possibly linked by atmospheric interactions over large distances.

In another dramatic decline, catches of the commercially harvested Dungeness crab near San Francisco collapsed from 12 million pounds to less than a million pounds in the late 1950s, just after the major El Niño of 1957-1958. Several explanations have been proposed, among them a permanent shift in ocean conditions. The cause of the decline is still not known with certainty.

Further north, in Northern California, Oregon and Washington, Dungeness crab catches go through regular cycles of about 10 years. Since the late 1970s, research has focused on the causes of the cycles, so that they might be managed to avoid these boom-andbust cycles. Groups at UC Davis and Humboldt State University used mathematical models combined with field data to show how the negative influences of adult crabs on recruitment of juveniles (including cannibalism of adults on newly settled juveniles and density-dependent fecundity) could contribute to these cycles.

Research since the mid-1980s has indicated that annual variability in the way currents transport the planktonic larvae of crabs and other species also

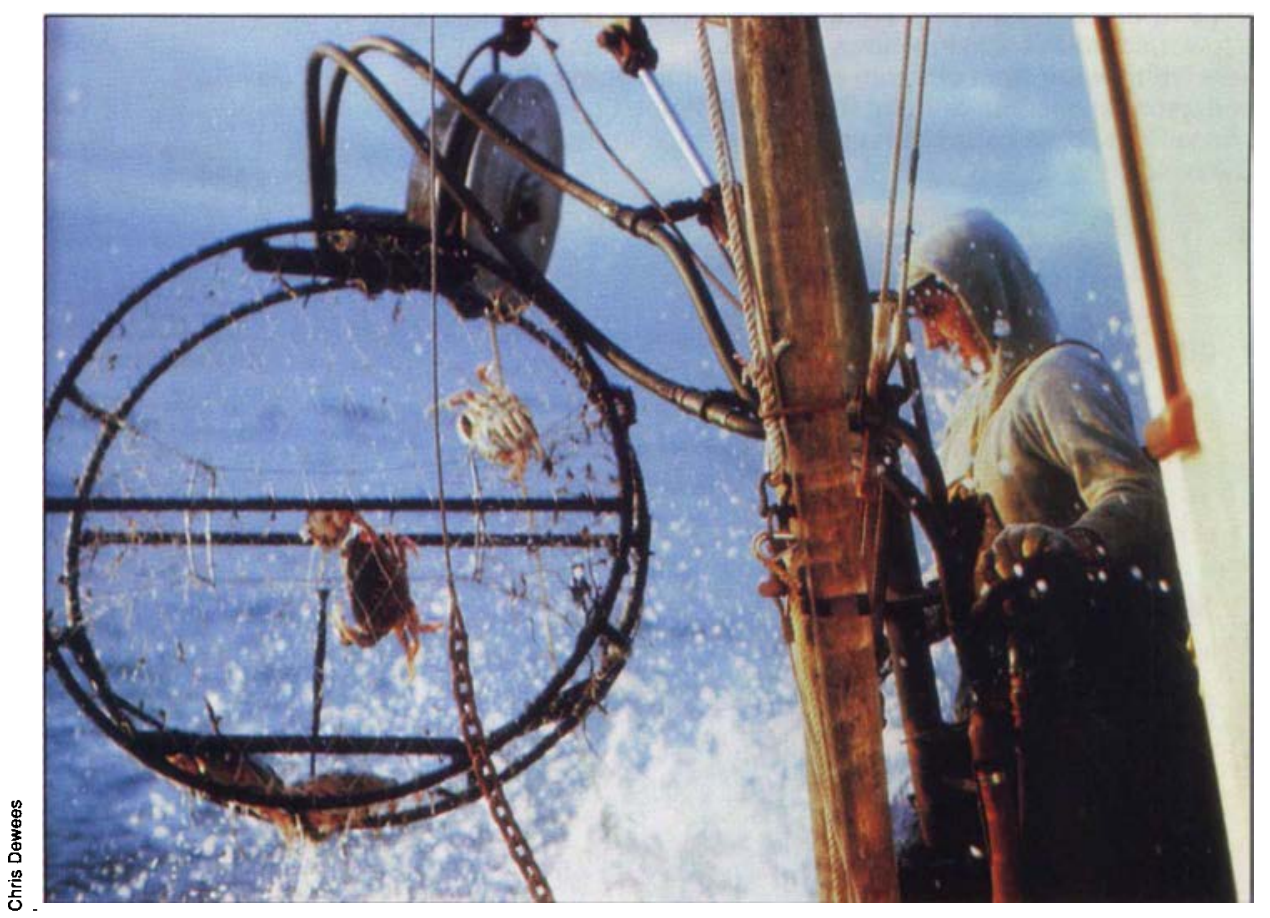

A commercial fisher hoists aboard a crab trap with a meager catch. Although catches are highly variable, most fisheries managers believe the Dungeness crab population is healthy.

has a critical effect on their population booms and busts. Data from Russian plankton cruises off the California coast indicate that Dungeness crab larvae disperse several hundred kilometers offshore, but may be transported back toward suitable nearshore habitat by migrating vertically between layers of water flowing in different directions. Modeling studies have shown that the timing of egg hatching and larval release into the plankton relative to the timing of the "spring transition" to the upwelling season also has a critical effect on the number of Dungeness crab larvae that successfully return to near shore. Other modeling studies of the Dungeness crab subpopulations from Northern California to Washington have shown that the patterns of larval dispersal between subpopulations can have a critical effect on whether populations cycle and how synchronous these cycles are along the coast (Botsford et al. 1994).

Researchers at UC Davis have recently shown how upwelling and relaxation also affect the alongshore dispersal of planktonic larvae along the coast. They have found that the larvae of fish and shellfish are not washed away to Southern California in the upwelling jet, but are retained in the lee side of promontories such as Point Reyes during strong upwelling (Wing et al. 1995). Then, during periods of upwelling relaxation, when winds cease or reverse for a few days, these larvae are transported northward, where they settle to the bottom along the coast. Such upwelling shadows occur at several points along the coast, and they may be important in maintaining persistent populations in spite of strong upwelling in Northern California. Researchers at the Moss Landing Marine Laboratory of the California State University system are investigating the impact of similar transport processes on rockfish recruitment (see page 41).

Monitoring of California's valuable red sea urchin fishery by UC Davis researchers has also revealed a pattern of settlement consistent with this mechanism of upwelling and relaxation. Size distributions of urchins collected along the coast indicate a settlement event in 1992 (fig. 3) in which there was substantial settlement to the north of Point Reyes and Point Arena, where it would be expected during upwelling relaxation, but very little 
Fig. 3. Size distributions of the shells of red sea urchins collected in 1995, showing a recruitment event that occurred in 1992 (a bump in the lower sizes) at some locations. There is greater recruitment where warm water from offshore of Point Arena (Albion, Elk, Gunderson) and south of Point Reyes (Salt Point, Ft. Ross Reef, Bodega Head) have carried larvae to the coast. (Figure by S. Wing, UC Davis.)

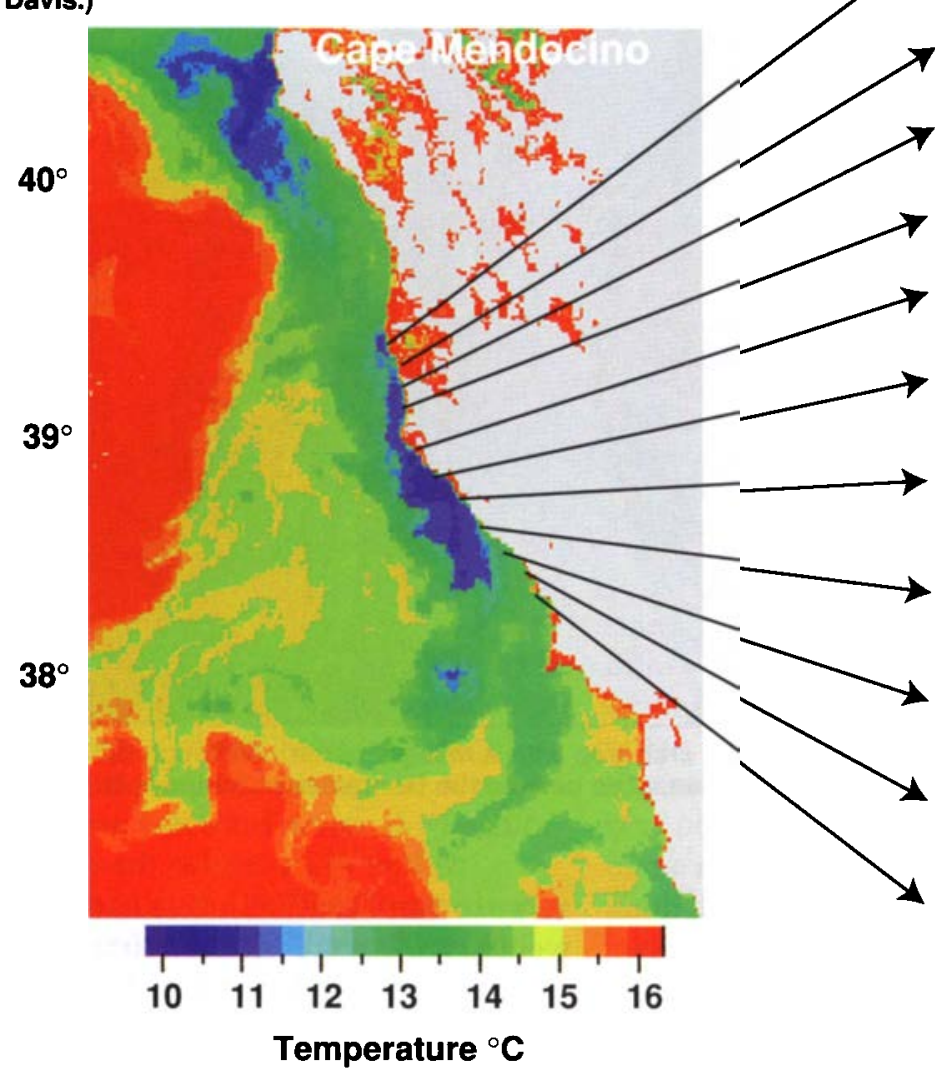

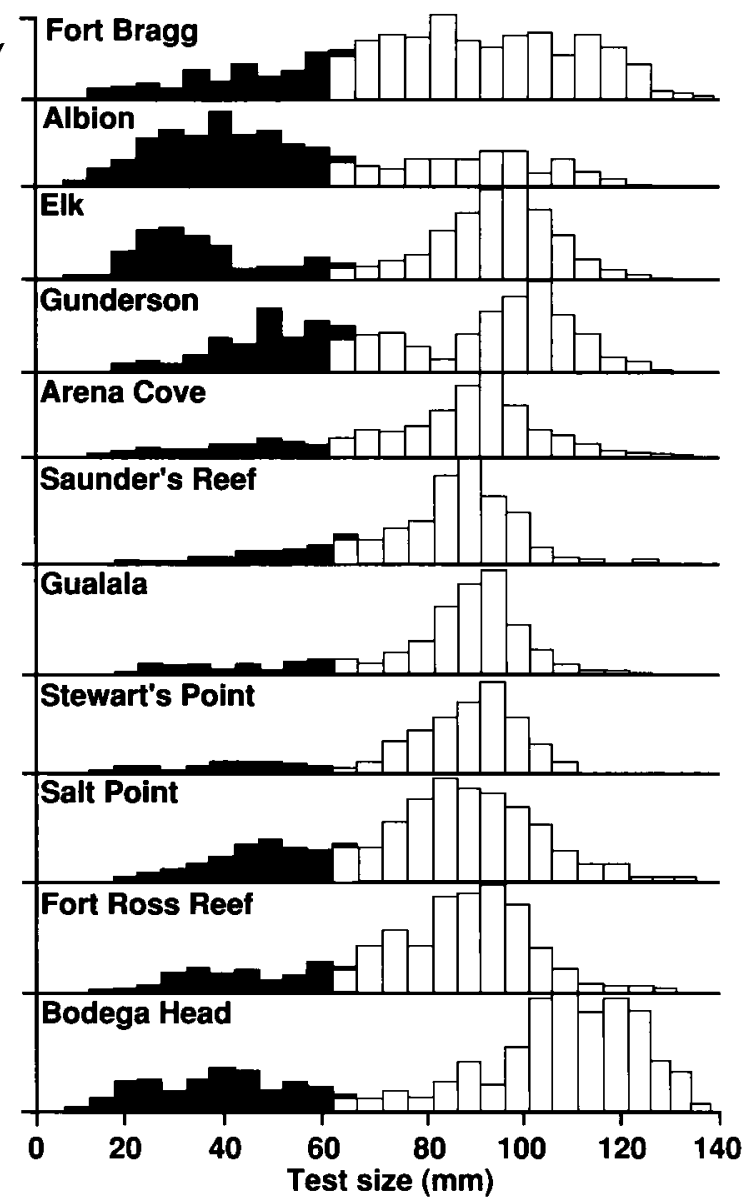

settlement elsewhere. This information is to being used to develop new, more efficient harvesting strategies for this fishery.

Populations of the two species of Pacific salmon that once supplied a prodigious harvest off California's shores appeared to fluctuate in cycles related to those in the Dungeness crab population during the 1950 s through the 1970s, but more recently have been dominated by decline (see California Agriculture Nov.-Dec. 1995). One of the runs of chinook salmon on the Sacramento River is listed under the federal Endangered Species Act, and others are proposed. Catch of coho salmon has declined over the past several decades, and some of these stocks are listed under both the state and the federal Endangered Species Acts, while others are proposed at both levels of government. At the same time, there has been a dramatic increase in Alaska salmon stocks and a glut in the Alaska market. We need to know how much the regime shift in the 1970s contributed to both the increase in Alaskan salmon stocks and the concomitant decline in salmon stocks off the West Coast of the contiguous United States by altering the relative split of the North Pacific Current (Pearcy 1992).

\section{The next decade}

These examples illustrate how our understanding of the coastal ocean has progressed steadily over the past 40 years, but it is still not adequate to resolve the problems that confront us. Although we understand some of the biological responses to physical changes, we do not completely understand the processes controlling the abundance of even one single population.

The general reason for wanting to understand the natural fluctuations of populations is to reduce uncertainty. One of the oldest marine problems, overfishing, is a good example of the general effect of uncertainty on resource management. Overfishing re- sults from the fact that managers are under considerable political and social pressure to increase allowable catches, but fisheries scientists are not able to tell them with certainty how much fishing is too much, nor whether an ongoing decline in a fishery is due to overharvesting or to natural causes. The consequence of this interaction is increased harvest pressure.

This combination of political pressure on the one hand and scientific uncertainty on the other is present in all of the threats facing the marine environment. Research on natural change in marine populations can reduce this uncertainty. To be politically viable, solutions to resource problems (like application of the Endangered Species Act) must be supported by an ability to differentiate the effects of human activities from those of natural change.

A number of harvested species worldwide have shown dramatic declines. Species now in danger of continued on p. 43 


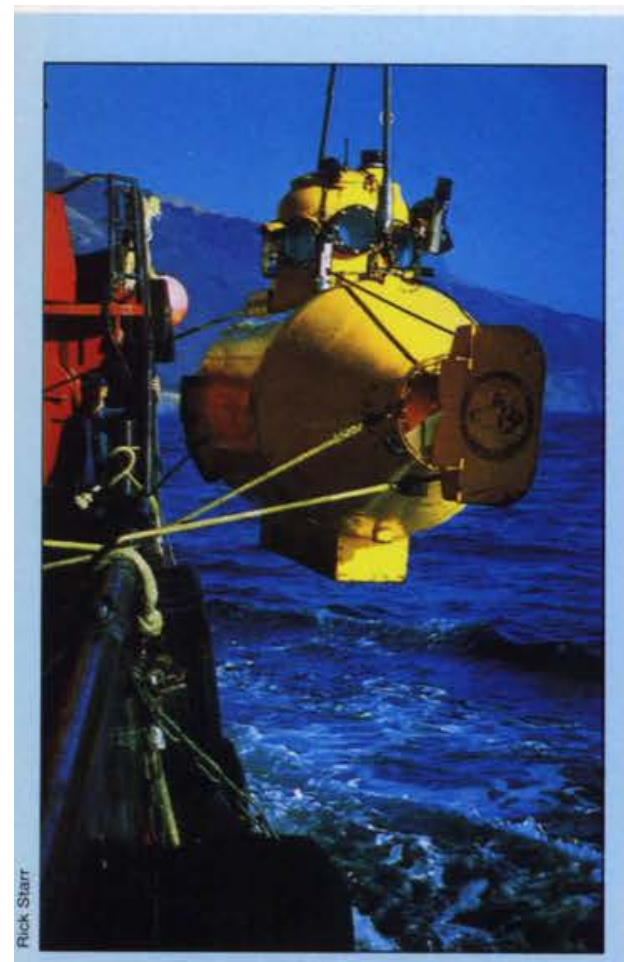

The submersible's pilot and a scientist conduct visual strip transects of rockfish habitats to identify species, describe fish behavior and count the number of rockfish observed in each transect.

the value of marine reserves and their potential for enhancing fisheries. We expect that the results will directly contribute to the effective management of marine fishery reserves in California and provide valuable information to fishery managers in all parts of the world.

R.M. Starr is UC Cooperative Extension, Sea Grant Marine Advisor for Monterey and Santa Cruz Counties.

\section{References}

McEvoy AF. 1986. The Fisherman's Problem: Ecology and Law in the California Fisheries, 1850-1980. New York: Cambridge Univ $\mathrm{Pr}$.

Rowley RJ. 1994. Marine reserves in fisheries management. Aquat Conserv: Marine Freshwater Ecosys 4:233-54.

Starr RM, Fox DS, Hixon MA, et al. 1996. Comparison of submersible and acoustic estimates of fish density on a rocky bank. Fish Bull 94:113-23.

Yoklavich MM, Cailliet GM, Greene HG, Sullivan D. 1995. Interpretation of sidescan sonar records for rockfish habitat analysis: Examples from Monterey Bay. Alaska Dept. Fish and Game Special Publication No. 9:11-5. continued from p. 40

extinction are the most extreme examples. Recovering endangered species requires identification of the causes of decline, and there is almost inevitably some confounding of natural and human causes. We simply don't know enough to untangle the threads. For example, the dams on the Snake River, where endangered stocks of Columbia River chinook salmon spawn, were completed in the mid1970 s, about the same time as the regime shift in the northeast Pacific. Another example, closer to home, is the decline in coho salmon over the past decade, during the period following the regime shift in the $1970 \mathrm{~s}$, but accompanied by increasing diversions in California's coastal streams and, until recently, by high harvest rates.

One possible cause of major alterations in the biological productivity in California's coastal ocean is climate change, which could cause dramatic changes in coastal populations by increasing the frequency or intensity of ENSO events, or by increasing upwelling (Bakun 1990). The decline in zooplankton biomass off Southern California is an example of long-term change that may be due to change in climate.

The advances of the past several decades have brought us closer to the answers we need by sharpening our focus on the time and space scales at which important processes operate. Ecologists, oceanographers and meteorologists realize that an important requirement for solving a problem is choosing the proper temporal and spatial scale at which to approach it. One example is the recent appreciation of the fact that large changes in marine environments are taking place on a global scale. The apparent synchrony of various dramatic shifts in population abundance in different parts of the world, and a realization of the possible atmospheric linkages across ocean basin scales, are allowing us to link events that previously seemed isolated.

This increase in the scope of marine population questions may encompass some of the keys to understanding these shifts in abundance. One advan- tage of a global perspective is the gain in analytical power possible through a comparative approach. Conclusions are often hampered by the limited time spans of available population data. By increasing the number of "experimental replicates" through a comparative approach, we have essentially increased the amount of available data. In addition to the shift in focus of spatial scale, oceanographers have recently realized that biological processes change on longer time scales (50 years or more), most likely in response to large-scale fundamental changes in the physical state of the atmosphere and ocean.

Another shift in the scale of research focus is our increased awareness of the importance of circulation near promontories and changes in upwelling on weekly time scales in maintaining coastal populations and biological communities. Even though we are interested in changes in recruitment from year to year, we need to look within years to describe the mechanisms responsible for longer term changes. With regard to spatial scales, we are interested in population levels and ecosystem health along the entire coast, but we may be able to manage better by taking advantage of the variability in productivity and circulation on much smaller scales, such as those shown in figure 3 . One growing trend in the management of coastal ecosystems is the use of protected areas or reserves. The design of management strategies involving protected areas requires understanding variability in productivity and larval dispersal on these scales.

UC and Sea Grant will continue to contribute to the solution of problems in the coastal ocean. There is every indication that Sea Grant will continue to support research on how changing ocean conditions affect biological resources. Other planned programs include the Coastal Ocean Processes in the National Science Foundation (NSF) and the GLOBEC program of NSF and the National Oceanic and Atmospheric Administration (NOAA). Both of these programs are starting up this year, and will run over the next 5 to 10 years. International linkages are being 


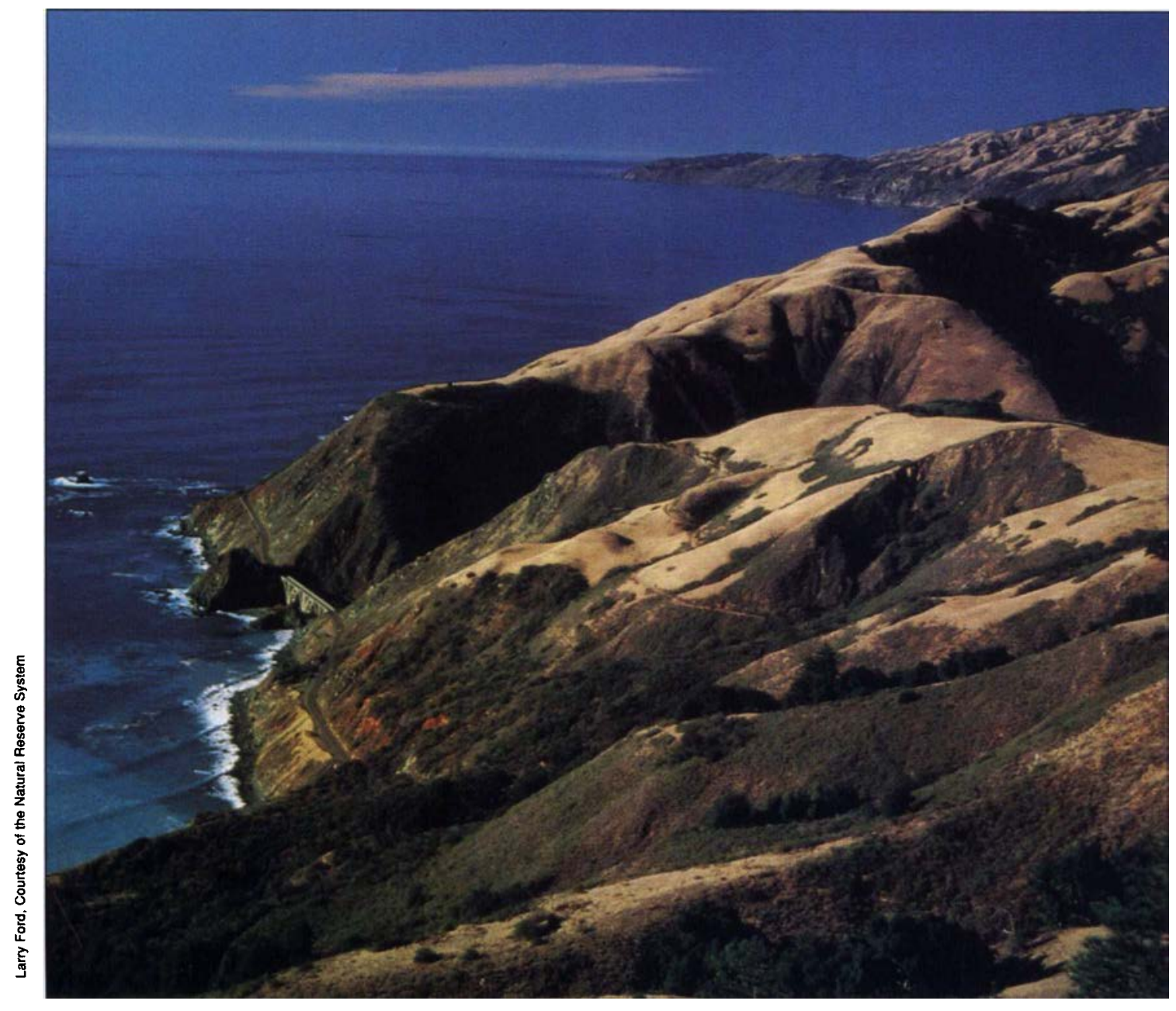

There is a growing trend to manage coastal ecosystems using protected areas or reserves. Big Creek Ecological Reserve, shown above, is on the coast of Monterey County, $\mathbf{2 0}$ miles south of Big Sur.

sardine and northern anchovy populations over the past two millennia from sediments of the Santa Barbara Basin. CalCOFI Report. 33:24-40.

Botsford LW, Moloney CL Hastings A, et al. 1994. The influence of spatially and temporally varying oceanographic conditions on meroplanktonic metapopulations. Deep-Sea Res II 41:107-145.

Chelton DP, Bernal PA McGowan JA. 1982. Large-scale interannual physical and biological interactions in the California Current. J Marine Res 40:10951125

Mann KH, Lazier JRN. 1996. Dynamics of marine ecosystems: Biological-physical interactions in

formed to coordinate research on similar marine species in similar ecosystems (for example, eastern boundary upwelling areas) throughout the world, and to enhance research capabilities in countries with less technology and resources than the United States. UC will continue to contribute to this research area through the Scripps Institution of Oceanography at UCSD, the Marine Science Center at UCSB and Long Marine Laboratory at UCSC. Also, UC's Bodega Marine Laboratory is considering initiation of a program to study the local marine environment. Other participants will include the Moss Landing Marine Laboratory and Humboldt State University, both of which maintain active research and teaching programs and research vessels. National Marine Fisheries Service scientists will continue to play a leading role.

We expect the next decade of research in California's coastal ocean to be exciting and productive, and we hope to gain the knowledge necessary to maintain the biodiversity and potential for food production in this valuable natural resource, our coastal ocean.

L.W. Botsford is Professor, Department of Wildlife, Fish, and Conservation Biology, UC Davis.

I would like to acknowledge the many dedicated marine scientists who have contributed to the results described here, whose work I did not have the space to reference in detail. I also thank John McGowan of Scripps Institution of Oceanography and Ted Strub of Oregon State University for their comments on this article.

\section{References}

Bakun A. 1990. Global climate change and intensification of coastal ocean upwelling Science 247:198-201.

Bakun A. 1996. Patterns in the Ocean: Ocean Processes and Marine Population Dynamics. La Jolla, CA. California Sea Grant College System. 339 p.

Baumgartner TR, Soutar A, Riedel W. 1994. Reconstruction of the history of Pacific the oceans. Blackwell Scientific.

Mullin M. 1995. Webs and scales. Univ Washington $\mathrm{Pr}$.

Parrish RH, Nelson CS, Bakun A. 1981 Transport mechanisms and reproductive success of fishes in the California Current. Biolo Oceanog 1:175-203.

Pearcy W. 1992. Ocean Ecology of North Pacific Salmonids. Seattle: Univ Washington $\mathrm{Pr}$.

Reid JL. 1962. On the circulation, phosphate-phosphorous content and zooplankton volume in the upper part of the Pacific Ocean. Limnol Oceanog 7:287-306.

Roemmich D, McGowan J. 1995. Climatic warming and the decline of zooplankton of the California Current. Science 267:1324-6.

Soutar A, Isaacs JD. 1974. Abundance of pelagic fish during the 19 th and 20 th centuries as recorded in anaerobic sediment of the Californias. Fish Bull 72:257-73.

Tegner MJ, Dayton PK. 1991. Sea urchins, EI Niños, and the long term stability of Southern California kelp forest communities. Marine Ecol Prog Ser 77:49-63.

Wing SR, Largier JL, Botsford LW, Quinn JF. 1995. Settlement and transport of benthic invertebrates in an intermittent upwelling region. Limnol Oceanog 40:316-29.

Wooster WS, Fluharty DL (eds.) 1985. EI Niño North: Nino effects in the Eastern Subarctic Pacific Ocean. Seattle: Univ Washington $\mathrm{Pr}$. 